Revista do Departamento de Geografia n. 13, 1999

\title{
PRÁXIS E NATUREZA
}

\author{
Alberto Lins Caldas *
}

\begin{abstract}
RESUMO
Refunda o conceito de natureza a partir de uma práxis e não como uma existência autônoma, pré-existente, condicionadora de sociedade. Para que haja natureza é preciso que se crie uma grade sócio-histórica e só assim pode haver compreensão. É a práxis quem determina aquilo que é natureza para uma sociedade assim como as visões que essa sociedade tem sobre o que é natureza.
\end{abstract}

Palavras-chave Natureza, sociedade, historicidade.

Não existe Natureza a não ser para uma sociedade. A idéia de ordem, de estrutura significativa, é fundamental como suporte daquilo que entendemos como natureza. Sem esse sentido não compreendemos; sentimos apenas desordem, caos, existência inexplicável (Casini, 1987). E, ao mesmo tempo, não possuímos um "modelo eterno" daquilo que entendemos como natureza, uma natureza metafísica girando e sendo descoberta, mas somente idéias, vivências, imaginários, práxis vivas historicamente determinadas, isto é, não temos uma natureza, mas as naturezas de diversas culturas em seus diversos momentos e uma infinidade de concepções de natureza da própria cultura ocidental.

A práxis, ao ir se constituindo como processo vital e em cada momento constituído, criação-trabalho, projeta-se comunitariamente introjetando-se enquanto "imagem" externa reconhecível; espaço/cartografia/paisagem como expressões de si, tornando o "reconhecimento" e a "exterioridade" como autonomias, necessariamente desligados daquilo que, social e historicamente, os constituiu.

A práxis como processo de formação-do-existente constitui a exterioridade como condição inescapável do trabalho e da vida humana, criando, no informe e no precário, a ordem necessária a existência da interioridade. Cria a maneira de conceber-se e conceber a exterioridade, seja "natural" ou social. Seu "objeto" estará sempre marcado por esse inescapável olhar social; olhar que só pode contemplar o trabalho da interioridade e a interioridade do trabalho enquanto existente. Como é criador da forma e do significado, encontrará sempre ele mesmo projetado enquanto ser social, fundamento da "vida prática" e das "teorias práticas" e não

(*) Departamento de História - UFRO 
de "metafísicas" que busquem um olhar divino ou inumano como base implícita para o existente.

A presença, sendo necessariamente histórica e social, condiciona o existente a ter sempre sentidos e formas compatíveis com essa historicidade fundante. A natureza não existe como um em-si kantiano (coisa que ninguém admite ao considerar a existência de uma natureza), mas através-do-social: cada universo humano terá oseu-existente, a sua natureza, a exterioridade compatível com sua atividade vital plasmada enquanto olho, mão, fala, crença, pensamento, ação e criatividade. Jamais estamos livres com o metafísico existente (somente um deus já separado do cosmo e da comunidade por uma crescente reformulação do sagrado e do profano poderia saber o existente); como seres sociais, a contrapartida da sociedade é uma exterioridade que reflete essa ordem em forma de ordem natural.

Quando o "algo" possibilita conceitos, imagens, filosofias, histórias e crenças é porque já não há esse "algo", mas aquilo que poderá ser chamado Natureza, estrutura e significado. Como nesse processo "quem" imprime sentido é a sociedade, o que se constitui é uma projeção viva de todos os "códigos" significativos daquela sociedade. A natureza, assim, é criada, como o sentiram inversamente todas as crenças do mundo, não como resultado de "forças divinas", "forças da matéria" ou "forças do espírito", mas como projeção vital da práxis. Os criadores ou o criador, na verdade, sempre foram as sociedades e seus modos específicos de viver.

A práxis, ao mesmo tempo que cria a natureza como projeção viva de si, cria também os limites e os deslimites "teóricos" para o entendimento dessa "exterioridade"; cria as múltiplas possibilidades do significado na compreensão de si mesmo, mas não pode superar sua própria existência projetiva, que é essencialmente historicizante, existindo em horizontes além do teórico; podendo somente limitar-se ao deslimite de si mesma, porque o deslimite, como "espaço" histórico, é tão somente uma perspectiva do limite. A práxis não pode ser um além-de-si, mas ilimitadas possibilidades significativas em si e para si mesma: a multiplicidade virtual é sempre uma determinada multiplicidade.

Por maior e mais verdadeiro que seja o universo para uma sociedade, desaparecendo esta sociedade, para quem será esse universo? Existirá assim sem a presença humana, sem o suporte de determinada práxis que o criou enquanto um amálgama comunitário entre trabalho e poíésis? Normalmente todos os universos, todas as naturezas, têm como fundamento uma existência metafísica que, mesmo não admitida como na nossa atual ocidental concepção de universo ou natureza, é quem garante certa legitimidade e objetividade ou, pelo menos, certo horizonte de mistério necessário (Bachelard, 1974). Mesmo que se chegue ao "como é realmente" o universo, desaparecendo o suporte desaparece também a imagem, o sentido, a estrutura (Durand, 1997): não há objeto sem sujeito: não há existente sem comunidade: ou melhor, um existente sem comunidade só o será para uma consciência, no caso, divina e como não estamos fazendo teologia devemos enfrentar conseqüentemente a questão da relação viva e criativa entre sujeito e objeto, entre determinada comunidade humana e o que ela chama de realidade, exterioridade ou natureza.

A "relação" entre o humano e o existente, que é antes de tudo relação entre homens, fundando aquilo que denominamos Natureza, é "escamoteado" pela Razão, não por um processo de falsificação, mas pela própria estrutura e função da racionalidade ocidental, sendo ela também jamais coisa "Humana", que é tornar as racionalidades ocidentais e principalmente a racionalidade científico-burguesa essência universal. Essa racionalidade não coloca ali nenhuma gran- 
de "espécie de contra-senso fundamental", mas identidade onde deveria haver contradições vivas, vazios e rarefações criativas, espaços imaginários deformados e deformantes de pura eletricidade/desejos/sonhos/fome/gozo.

O limite de uma "ilusão cultural", onde todo existente para a comunidade tem sentido e estrutura, desaparece para dar lugar ao deslimite do universal, onde essa ilusão, no caso ocidental, extrapola-se para desejar se tornar a realidade de todos e uma realidade além de si mesma, negando seus próprios fundamentos sociais e históricos. Nesse momento sua panrrealidade, mega naturalização universalizante do seu modo de produção, torna-se uma metafísica profundamente frágil teoricamente (não tem um deus para suportá-la) mas interessantemente proveitosa em termos bélicos, comerciais e ideológicos.

A Razão põe no lugar do "inferno criativo básico", relações vivas de trabalho, modelos, sistemas, estruturas de pura identidade, paisagens bucólicas ou propriedades. Põe até o "contra-senso", não um amálgama lúdico e doloroso entre o Caos e a Criação, entre o permanente e necessário fluxo de contradições e o absoluto; relações vitais que criam-se ao criarem-se como práxis. Esse fundamento mefistofélico do humano se dá como criador e conseqüência de toda criação social. Mas o aparecer dessas relações e os modelos racionais não são infernais, magmáticos, demiúrgicos; são sistemas integrados pelo conceito, pela idéia, pela ordem; mostram-se como imagens do poder e imagens de como o poder se concebe (Foucault, $1968,1985,1987)$. Sendo a "racionalidade do senhor" (Adorno, 1985) não poderia reproduzir nem seu real fundamento nem os "fornos do demônio", principalmente porque tanto o "trabalho" quanto a força de trabalho não são desvendados pelas perspectivas reificadoras. A práxis não acontece fora de uma formatação social, fora do âmbito das relações humanas, relações de distribuição e produção, poder, status, estamentos, classes, castas (Vásques, 1977); jamais uma práxis partindo do nada para o nada; o demiúrgico do homem é sempre um modelado modelar.

Mas não podemos perder de vista que, se no limite há e deve haver uma poíésis dialética e historicizante, garantia mínima de sentido e significado, no centro a questão não é nem poética nem relativa, mas política, ideológica e, necessariamente, de classe. Se o conjunto das nossas concepções de natureza são historicizadas, elas perdem, no limite, a universalização naturalizada produzida no centro das classes que produzem ideologia (Marx, 1976; Mészáros, 1993,1996). A universalização da natureza é um duplo da universalização pretendida pelas "classes dominantes", ou melhor, pelas classes que detêm os poderes e as possibilidades de torná-los tendência de hegemonia através de uma práxis alienada e de teorias que expressam essas mesmas classes. E no centro a questão se desloca para uma luta política onde as perspectivas revolucionárias podem, no seu momento, destravarem as ideologias, as imagens e percepções, criando uma contra-idéia, mas nunca aceitando a objetividade do outro, o universo e a natureza do outro. Tanto uma concepção de Estado ou de Sociedade fazem parte do mesmo sistema, a mesma lógica que gera uma concepção de realidade e natureza. Não se pode aceitar ingenuamente tanto uma concepção de Estado quanto uma concepção de natureza que se enraízem metafisicamente nas estruturas ideológicas que se pretende combater. A questão da natureza não é uma questão de realidade mas de como para nós socialmente se instaura o real.

Em Marx $(1975,1977)$ enquanto no centro sua concepção de realidade e natureza são políticas e diretamente históricas, no limite são 
racionalistas, cientificistas, tipicamente ocidentais, aceitando sem contestação a visão de mundo ideológica da ocidentalidade. A rutura marxiana se faz somente no centro, sem levar essa rutura consequentemente até o limite. Já a lógica geral de produção de mundo no capital, lógica essencialmente monofônica e exclusivista, produz uma mesma concepção de natureza tanto no limite quanto no centro. Enquanto o limite precisa ser "despolitizado" para ser, conter e expressar a poíésis fundante, o centro precisa ser "despoetizado" para ser repolitizado. A questão da natureza exige múltiplas e flexíveis lógicas de reflexão (Caldas,1997) para se desdobrar e se tornar significativa.

Os poderes reformatam o aparecer (desde o momento da própria produção/criação, inclusive essa criação faz parte dessa formatação) e o harmonizam com um pretenso conteúdo, equilibrando o dentro e o fora, a essência e a aparência, forma e conteúdo. Sem essa formatação a Razão perderia sua funçắo principal, que não é compreender, mas modelar. Essa simulação (que é, na verdade, o conhecimento-da-Razão, talvez a própria Razão) rapta toda a força radical da criação, do fundamento negativo do humano enquanto ser criador porque é ele autocriador. $\mathrm{O}$ "resulta- do" é sempre um mundo hiper-conceitualizado (natureza aparecendo como paisagem ou propriedade, não como criação humana), em ordem ou, no máximo, em sistemas que oscilam levemente. Jamais o inferno da criação. Atravessamos a vida sem alcançar esse princípio criativo básico porque sendo a comunidade esse centro demiúrgico, vêla representaria estar fora-de-um-mundo-dominante-legítimo que elabora todas as suas visões a partir de homens reais sempre alienados, presos a relações de trabalho em específicas sociedades de classe, vendo principalmente objetos e, não raras vezes, a si mesmo como objeto-da-terra, objeto-dosenhor, objeto-de-deus ou simples objeto.

A Razão apresenta-se sempre como Simulatio post mortem, mas o morto não apresenta-se como um simples morto destroçado pela doença ou pelo acidente que o devorou, mas como manequim, pintado/maquiado para não horrorizar, simulação do morto: os frutos da Razão são manequins cínicos. A Natureza ocidental é um dos manequins dessa Razão. Um imenso holograma estruturado pelas mesmas lógicas que criam realidade, imaginário e objetificação.

\section{BIBLIOGRAFIA}

ADORNO, T.; HORKEHEIMER, M. Dialética do Esclarecimento. Rio de Janeiro, Jorge Zahar, 1985.

ARIÈS, P. O tempo da História. Rio de Janeiro, Francisco Alves, 1989.

BACHELARD, G. La formación del Espiritu Cientifico. 2. ed. Siglo Veintiuno, Buenos Aires, 1974.

. O Racionalismo Aplicado. Rio de Janeiro, Zahar, 1977a. . O novo Espírito Científico. In Col. Os Pensadores. São Paulo, Abril Cultural, 1978b.

BAUDRILLARD, J. O sistema dos objetos. Série Debates/70, 2. ed. São Paulo, Perspectiva, 1989.
BOURDIEU, P. O poder simbólico. Rio de Janeiro, Difel/ Bertrand Brasil, 1989.

CALDAS, A. L. Dialética e hermenêutica: Uma questão de método. In: GEOUSP-Revista da Pós-Graduação em Geografia, n. 1, Universidade de São Paulo - USP, p. 23-29, São Paulo, 1997.

. Interpretação e realidade. Caderno de criação, UFRO/ Dep. de História/CEI, n. 13, ano IV, Porto Velho, setembro, 1997.

CASINI, P. As filosofias da natureza. Lisboa, Editorial Presença, 1987. 
CASTORIADIS, C. A instituição imaginária da sociedade. 3. ed. Rio de Janeiro, Paz e Terra, 1991.

CLAVAL, P. Espaço e Poder. Rio de janeiro, Zahar, 1979.

DOLLFUS, O. O espaço geográfico. São Paulo, Difel, 1982.

DUARTE, R. A. de P. Marx e a Natureza em o Capital. São Paulo, Loyola, 1986. Col. Filosofia/4.

DURAND, G. As estruturas antropológicas do Imaginário. São Paulo, Martins Fontes, 1997.

ENGELS, F. Dialectica de la naturaleza. México, Editorial Grijalbo, 1961.

FOUCAULT, M. As palavras e as coisas. Lisboa, Portugália, Col. Problemas/23, 1968.

Microfísica do poder. 5. ed. Rio de Janeiro, Graal, 1985. . Vigiar e punir. Petrópolis, Vozes, 1987.

ISNARD, H. O espaço geográfico. Coimbra, Almedina, 1982.

LUKÁCS, G. História e consciência de classe. Porto, Publicações Escorpião, 1974.

- Ontologia do ser social: os princípios ontológicos fundamentais de Marx. São Paulo, Livraria Editora Ciências Humanas, 1979a.

. Ontologia do ser social: a falsa e a verdadeira ontologia de Hegel. São Paulo, Livraria Editora Ciências Humanas, 1979b.

MARX, K. O capital. 3. ed. Rio de Janeiro, Civilização Brasileira, 1975. . A ideologia alemã. 3. ed. Lisboa, Presença, 2 vol., 1976. . Contribuição à crítica da economia política. São Paulo, Martins Fontes, 1977.

MÉSZÁROS, I. Marx: A teoria da alienação. Rio de Janeiro, Zahar, 1981.

. Filosofia, ideologia e ciência social. São Paulo, Ensaio, 1993.
O poder da ideologia. São Paulo, Ensaio, 1996.

MORAES, A. C. R. Ideologias geográficas. São Paulo, Hucitec, 1988.

;COSTA, W. M. da. 2. ed. Geografia crítica: A valorização do espaço. São Paulo, Hucitec, 1987.

. Meio ambiente e ciências sociais. São Paulo, Hucitec, 1994.

MOSCOVICI, S. Sociedade contra natureza. Petrópolis, Vozes, 1975.

QUAINI, M. Marxismo e geografia. Rio de Janeiro, Paz e Terra, 1979.

SANTOS, M. Por uma geografia nova. São Paulo, Hucitec, 1978. Espaço e método. São Paulo, Nobel, 1985. Col. Espaços,

SCHAMA, S. Paisageme memória. São Paulo, Companhia das Letras, 1996.

SCHIMIDT, A. El concepto de naturaleza en marx. México, Siglo Veintiuno, 1976.

SILVA, A. C. da. O espaço fora do lugar. São Paulo, Hucitec, 1978.

THOMAS, K. O homem e o mundo natural. São Paulo, Companhia das Letras, 1988.

TUAN, Y. Topofilia: Um estudo da percepção, atividades e valores e o meio ambiente. Rio de Janeiro, Difel, 1980.

Espaço e lugar: a perspectiva da experiência. Rio de Janeiro, Difel, 1983.

TURNER, F. O espírito ocidental contra a natureza. Rio de Janeiro, Campus, 1990.

VÁZQUES, A. S. Filosofia da praxis. 2. ed. Rio de Janeiro, Paz e Terra, 1977.

WHITEHEAD, A. N. O conceito de natureza. São Paulo, Martins Fontes, 1994.

\begin{abstract}
Make deeper the concept of natur from a praxis and not as a pre-existing society conditioning being. In order to the nature exist it is necessary to create a socio-historical grid and only then it is possible to have compreension. It is the praxis which determines what is nature to a society such as the visions that this society has about what is nature.
\end{abstract}

Keywords Nature, society, historicity. 